Fakultät III

Wirtschaftswissenschaften, Wirtschaftsinformatik und Wirtschaftsrecht

Volkswirtschaftliche Diskussionsbeiträge

Discussion Papers in Economics

No. $166-14$

July 2014

Thomas Eichner · Rüdiger Pethig

Stable and sustainable global tax coordination with Leviathan governments 
Universität Siegen

Fakultät III

Wirtschaftswissenschaften, Wirtschaftsinformatik und Wirtschaftsrecht

Fachgebiet Volkswirtschaftslehre

Hölderlinstraße 3

D-57068 Siegen

Germany

http://www.wiwi.uni-siegen.de/vwl/

ISSN 1869-0211

Available for free from the University of Siegen website at

http://www.wiwi.uni-siegen.de/vwl/research/diskussionsbeitraege/

Discussion Papers in Economics of the University of Siegen are indexed in RePEc and can be downloaded free of charge from the following website:

http://ideas.repec.org/s/sie/siegen.html 


\title{
Stable and sustainable global tax coordination with Leviathan governments *
}

\author{
Thomas Eichner \\ Department of Economics, University of Hagen \\ Rüdiger Pethig \\ Department of Economics, University of Siegen
}

\begin{abstract}
Itaya et al. (2014) study the conditions for sustainability and stability of capital tax coordination in a repeated game model with tax-revenue maximizing governments. One of their major results is that the grand tax coalition is never stable and sustainable. The purpose of this note is to prove that there are conditions under which the grand tax coalition is stable and sustainable in Itaya et al.'s model.
\end{abstract}

JEL classification: H71, H77

Key words: $\quad$ global tax coordination, repeated game, sustainability, stability

*Eichner: Department of Economics, University of Hagen, Universitätsstr. 41, 58097 Hagen, Germany, email: thomas.eichner@fernuni-hagen.de; Pethig: Department of Economics, University of Siegen, Hölderlinstr. 3, 57068 Siegen, Germany, email: pethig@vwl.wiwi.uni-siegen.de 


\section{Introduction}

In their recent article in this Journal, Itaya et al. (2014) study the conditions for sustainability and stability of capital tax coordination in a repeated game model with tax-revenue maximizing governments. They combine the issue of coalition formation taking advantage of the stability concept of d'Asprement et al. (1983) and the issue of sanctions designed to enforce compliance of the signatories of tax coordination treaties with the agreed obligations. With $N$ denoting the total number of countries and $S^{*}$ denoting the number of countries in the sustainable and stable tax coalition, they find $S^{*}=0$ for $N<10, S^{*}=7$ for $N=10$ and $S^{*}=6$ for $N \geq 11$. The important point and the focus of the present note is that in the model of Itaya et al. (2014) the grand coalition is neither sustainable (ibidem, p. 270) nor stable (ibidem, p. 272). That result contrasts with Bucovetsky (2009)'s finding in a static tax competition model with heterogeneous population size and benevolent governments that the grand coalition may be stable under certain conditions. According to Itaya et al. (2014) the divergence of their result and Bucovetsky's stems from the fact that their model is symmetric while Bucovetsky's is asymmetric.

Closer inspection of global tax coordination in Itaya et al. (2014) shows that the grand coalition sets infinitely large tax rates which cause negative interest rates in the associated economies. At negative interest rates consumers do not supply capital and the capital market is not in equilibrium. In contrast, in this note we follow Bucovetsky (2009) and focus on feasible economies at which interest rates are positive such that capital market equilibria exist, and prove that there are conditions under which the grand tax coalition is both stable and sustainable in Itaya et al.'s model.

\section{The model}

Itaya et al. (2014) consider an economy with $N$ identical countries. In each country $i$ a representative firm produces a consumer good with mobile capital $k_{i}$ according to the production function $f\left(k_{i}\right) \equiv\left(A-k_{i}\right) k_{i}, i \in \mathbf{N}=\{1, \ldots, N\}$. For each unit of capital the firm in country $i$ pays the interest rate $r$ and the source-based capital tax rate $\tau_{i}$. Combing the first-order condition of profit maximization, $f^{\prime}\left(k_{i}\right)=A-2 k_{i}=r+\tau_{i}$, with the capitalmarket equilibrium condition $\sum_{h=1}^{N} N \bar{k}$, where $\bar{k}$ is the capital endowment of country $i$, we obtain the equilibrium interest rate and the equilibrium capital demand of country $i$,

$$
r^{*}=A-2 \bar{k}-\frac{\sum_{h=1}^{N} \tau_{h}}{N} \quad \text { and } \quad k_{i}^{*}=\bar{k}-\frac{\tau_{i}}{2}+\frac{\sum_{h=1}^{N} \tau_{h}}{2 N} \quad \forall i \in \mathbf{N} .
$$


Governments seek to maximize tax revenues $R_{i} \equiv \tau_{i} k_{i}^{*}$ and use them to finance public expenditures.

For later use as a benchmark, we briefly characterize the Nash equilibrium of the noncooperative game and the allocation in case of global tax coordination (grand coalition). In the non-cooperative game, each government government $i$ chooses the tax rate $\tau_{i}$ that maximizes $R_{i}$ for given tax rates $\left(\tau_{1}, \ldots, \tau_{i-1}, \tau_{i+1}, \ldots, \tau_{n}\right)$ which results in non-cooperative Nash equilibrium tax rates, investments and tax revenues

$$
\tau_{\mathbf{N}}^{N E}=\frac{2 N \bar{k}}{N-1}, \quad k_{\mathbf{N}}^{N E}=\bar{k} \quad \text { and } \quad R_{\mathbf{N}}^{N E}=\frac{2 N \bar{k}^{2}}{N-1} .
$$

In case of global tax coordination the grand coalition will increase its capital tax rate as long as the interest rate is positive (see also the Bucovetsky (2009, Proof of Proposition 8)). Therefore we need an upper bound on feasible tax rates to keep the interest rate nonnegative $\left(r^{*} \geq 0\right)$. Making use of this non-negativity constraint and symmetry in (1) and in the equation $R_{i}=\tau_{i} k_{i}^{*}$, we obtain the grand coalition's tax rates, investments and tax revenues ${ }^{1}$

$$
\tau_{\mathbf{G}}^{C}=A-2 \bar{k}, \quad k_{\mathbf{G}}^{C}=\bar{k} \quad \text { and } \quad R_{\mathbf{G}}^{C}=(A-2 \bar{k}) \bar{k} .
$$

In order to compare $\tau_{\mathbf{G}}^{C}$ and $R_{\mathbf{G}}^{C}$ from our equation (3) with the corresponding terms in Itaya et al., we invoke their equations (11) and (16) and find that $\tau_{\mathbf{S}}^{C}$ and $R_{\mathbf{S}}^{C}$ are undefined for $S=N$. This is so because for $S=N$ their function $R(N)=\sum_{h=1}^{N} R_{h}$ is strictly monotonically increasing in $\tau_{i}$. As an implication, their first-order condition (7) cannot be satisfied. The reason for the strict monotonicity of the function $R$ in all $\tau_{i} \geq 0$ is the failure to exclude negative interest rates. Specifically, it is easy to show that there is a threshold value, say $\tilde{\tau}>0$, such that the interest rate is negative for all $\tau_{i}>\tilde{\tau}$. In other words, Itaya et al. (implicitly) allow for negative interest rates although such rates are incompatible with capital market clearing. Imposing the non-negativity constraint on interest rates yields a unique maximizer and maximum of the function $R(N)$ as calculated in our equations (3). We now proceed investigating the impact of (3) on results.

\footnotetext{
${ }^{1}$ The superscript $C$ denotes the Nash subgroup equilibrium and the subscript $\mathbf{G}$ stands for the grand coalition.
} 


\section{Repeated game}

\subsection{Sustainability of the grand coalition}

In this subsection, we turn to the sustainability of the grand coalition in a repeated game. In every period, each country sets the grand coalition's tax rate $\tau_{\mathbf{G}}^{C}$ if all other countries have chosen $\tau_{\mathbf{G}}^{C}$ in the previous period. Once a country deviates, the grand coalition breaks down and countries are playing the non-cooperative Nash equilibrium forever. The grand coalition is sustainable if

$$
\frac{1}{1-\delta} R_{\mathbf{G}}^{C} \geq R_{i}^{D}+\frac{\delta}{1-\delta} R_{\mathbf{N}}^{N E}
$$

where $\delta \in(0,1)$ is the discount rate and $R_{i}^{D}$ is the tax revenue of the deviating country $i$.

Next, we determine the best deviation tax rate $\tau_{i}^{D}$. The deviating country maximizes its tax revenue assuming that all other $N-1$ countries stick to the grand coalition's tax rate $\tau_{\mathbf{G}}^{C}$. The corresponding first-order condition can be rearranged to read $\tau_{i}^{D}=\frac{N}{N-1}\left(\bar{k}+\frac{(N-1) \tau_{\mathbf{G}}^{C}}{2 N}\right)$. We insert $\tau_{\mathbf{G}}^{C}$ from $(3)$ in $\tau_{i}^{D}$, which turns (1) and the tax revenues into

$$
\tau_{i}^{D}=\frac{A}{2}+\frac{\bar{k}}{N-1}, \quad k_{i}^{D}=\frac{(N-1) A+2 \bar{k}}{4 N} \quad \text { and } \quad R_{i}^{D}=\frac{[A(N-1)+2 \bar{k}]^{2}}{8 N(N-1)} .
$$

Finally, plugging (2), (3) and (5) in (4) establishes the minimum discount factor that renders the grand coalition sustainable ${ }^{2}$

$$
\left.\delta(N)=\frac{R_{i}^{D}-R_{\mathbf{G}}^{C}}{R_{i}^{D}-R_{\mathbf{N}}^{N E}}=\frac{A(N-1)-2 \bar{k}(2 N-1)}{A(N-1)+2 \bar{k}(2 N+1)} \in\right] 0,1[.
$$

We summarize our results in

Proposition 1. In all feasible economies $(A, \bar{k}, N),{ }^{3}$ the grand coalition can be sustained as a subgame perfect Nash equilibrium in a repeated game of tax competition, if and only if $\delta>\delta(N)$.

\subsection{Stability of the grand coalition}

In this subsection we investigate whether the grand coalition is stable according to the stability concept of d'Aspremont et al. (1983). Before playing the repeated game, there is

\footnotetext{
$\left.{ }^{2} \delta(N) \in\right] 0,1[$ is shown in the Appendix.

${ }^{3}$ For the parameter restrictions defining the set of feasible economies see the Appendix.
} 
an initial stage at which countries decide whether or not to form the grand coalition. If the grand coalition exists, all coalition members choose tax revenues $R_{\mathbf{G}}^{C}$ from (2). If a country leaves the grand coalition, the world economy is attained to sustain the Nash subgroup equilibrium with $(N-1)$ coalition members in which the coalition's tax rate revenues are $R_{\mathbf{S}}^{C}(N-1)$ and the fringe country's tax revenues are $R_{\mathbf{N}-\mathbf{S}}^{C}(N-1)$ if and only if $\delta \geq \delta(N)$. Hence at the initial stage the payoffs of the grand coalition and non-cooperative country are

$$
\begin{aligned}
\Pi_{\mathbf{G}}^{C} & \equiv \begin{cases}R_{\mathbf{G}}^{C} /(1-\delta) & \text { if } \delta \geq \delta(N), \\
R_{\mathbf{N}}^{N E} /(1-\delta) & \text { otherwise },\end{cases} \\
\Pi_{\mathbf{N}-\mathbf{S}}^{C}(N-1) & \equiv \begin{cases}R_{\mathbf{N}-\mathbf{S}}^{C}(N-1) /(1-\delta) & \text { if } \delta \geq \delta(N), \\
R_{\mathbf{N}}^{N E} /(1-\delta) & \text { otherwise }\end{cases}
\end{aligned}
$$

If $\delta<\delta(N)$, the grand coalition is not sustainable and hence no tax agreement is signed in the first place. So we consider $\delta>\delta(N)$ in what follows. The grand coalition is stable, if it is internally stable, i.e. if

$$
R_{\mathbf{G}}^{C}>R_{\mathbf{N}-\mathbf{S}}^{C}(N-1) .
$$

Inserting $^{4} R_{\mathbf{N}-\mathbf{S}}^{C}(N-1)=\frac{2 N(N+1)^{2} \bar{k}^{2}}{9(N-1)}$ and $(3)$ in $(7)$ yields the equivalence

$$
R_{\mathbf{G}}^{C}>R_{\mathbf{N}-\mathbf{S}}^{C}(N-1) \quad \Longleftrightarrow \quad \frac{A}{2 \bar{k}}>1+\frac{N(N+1)^{2}}{9(N-1)}
$$

Proposition 2. In all feasible economies $(A, \bar{k}, N)$, the grand coalition is both sustainable and stable, if and only if $\delta>\delta(N)$ and $\frac{A}{2 k}>1+\frac{N(N+1)^{2}}{9(N-1)}$.

\section{References}

Bucovetsky, S. (2009): An index of capital tax competition, International Tax and Public Finance 16, 727-752.

D'Aspremont, C., Jacquemin, A., Gabszewicz, J.J. and J.A. Weymark (1983): On the stability of collusive price leadership, Canadian Journal of Economics 16, 17-25.

Itaya, J.-I., Okamura, M. and C. Yamaguchi (2014): Partial tax coordination in a repeated game setting, European Journal of Political Economy 34, 263-278.

\footnotetext{
${ }^{4}$ We take over the Nash subgroup equilibrium tax revenues $R_{\mathbf{N}-\mathbf{S}}^{C}(S)$ with $S=N-1$ from Itaya et al. (2014, equation (17)).
} 


\section{Appendix}

\section{The set of feasible economies}

We define the set of feasible economies as that set of economies which secures non-negative interest rates and full employment of capital in all relevant equilibria. In formal terms, we need to consider the following three parameter constraints.

(i) Capital is fully employed in the regime of global tax coordination if and only if

$$
\frac{A}{2 \bar{k}}>1
$$

(ii) Observe that $\tau_{\mathbf{G}}^{C}$ implies that the interest rate is zero. Hence if the inequality $\tau_{i}^{D}>\tau_{\mathbf{G}}^{C}$ would hold, the interest rate would be negative. To exclude that unrealistic case, we assume that the parameters satisfy

$$
\frac{A}{2 \bar{k}}>2+\frac{1}{N-1}=1+\frac{N}{N-1},
$$

which ensures $\tau_{\mathbf{G}}^{C}>\tau_{i}^{D}$.

(iii) Setting $S=N-1$ in Itaya (2014, equations (11) and (12)) we obtain the tax rates $\tau_{\mathbf{S}}^{C}(N-1)=\frac{2 N(2 N-1) \bar{k}}{3(N-1)}$ and $\tau_{\mathbf{N}-\mathbf{S}}^{C}(N-1)=\frac{2 N(N+1) \bar{k}}{3(N-1)}$ that prevail in the Nash subgroup equilibrium with $(N-1)$ coalition members and one non-coalition country. According to (1), the interest rate in that equilibrium is positive if $\tau_{\mathbf{G}}^{C}>(N-1) \tau_{\mathbf{S}}^{C}(N-1)+\tau_{\mathbf{N}-\mathbf{S}}^{C}(N-1)$ or, equivalently, if

$$
\frac{A}{2 \bar{k}}>1+\frac{2\left(N^{2}-N+1\right)}{3(N-1)} .
$$

To sum up, an economy $(A, \bar{k}, N)$ is said to be feasible, if $A, \bar{k}>0, N \in \mathbf{N}$ and if the inequalities (A1), (A2) and (A3) are satisfies. For $N>2$ we have $\frac{2}{3}\left(N^{2}-N+1\right)>N$ which implies $(\mathrm{A} 3) \Longrightarrow(\mathrm{A} 2) \Longrightarrow(\mathrm{A} 1)$. Hence the set of feasible parameters is

$$
F:=\{(A, \bar{k}, N) \mid A, \bar{k}>0, N \in \mathbf{N} \backslash\{1,2\} \text { and (A3) holds }\}
$$

\section{The minimum discount rate}

$\frac{A}{2 \bar{k}}>1+\frac{N}{N-1}$ is equivalent to $A(N-1)-2 \bar{k}(2 N-1)>0$. In addition, the numerator in (6) is smaller than the denominator in (6) which implies $\delta(N) \in] 0,1[$. 